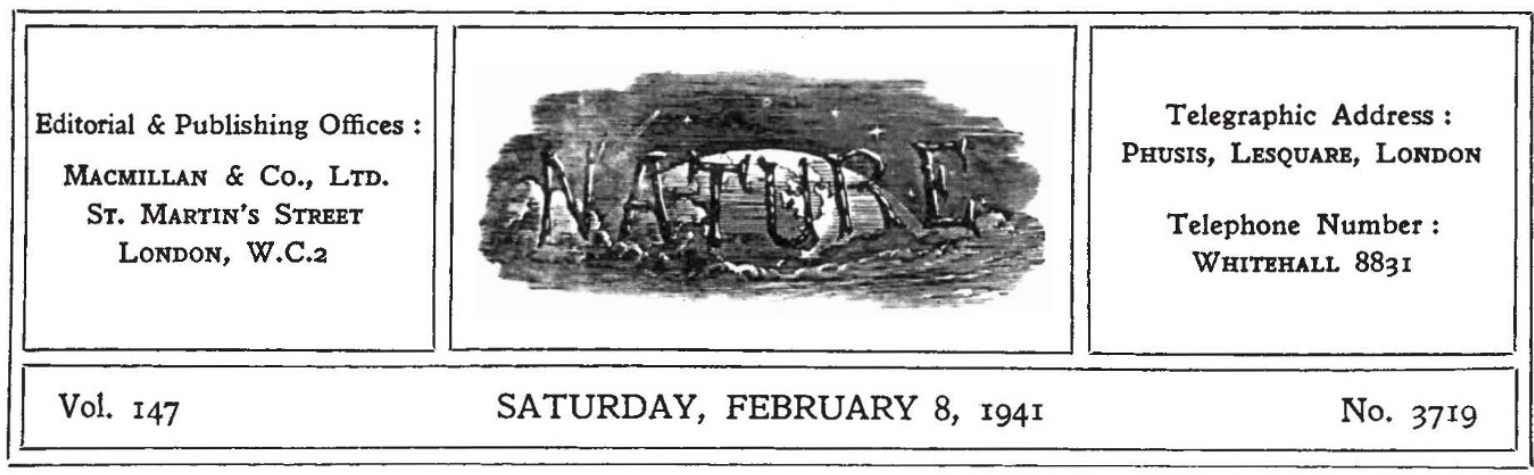

\title{
SELECTION OF SCIENTIFIC WORKERS
}

A CHARACTERISTIC of the present age of A the machine is the increasing use which is made in industry and elsewhere of the services of men and women with scientific or technical qualifications. This tendency was sufficiently apparent in peace-time, and the outbreak of war has intensified the demand. The active competition between the fighting services and industry for trained workers has already given cause for anxiety, which is reflected in the recent 'calling up' regulations referring to the 'reservation' of students of science and technology at school or university.

While it is generally agreed that a certain standard of training is essential for those who wish to take up a scientific or technical career, there is not so much known about the actual conditions under which scientific men in industry carry out their work, or of the personal qualifications which are desirable. Dr. Charles S. Myers, who is honorary scientific adviser to the National Institute of Industrial Psychology, has discussed some psychological aspects of these problems in Occupational Psychology (15, No. 1, 26 ; 1941).

The term 'scientific worker' is often used somewhat vaguely and it would be difficult to give any definition that would be considered adequate. In general, Dr. Myers refers to the professional scientific worker on the staff of an industrial or commercial organization, or of a Government department. He classifies such workers into three main groups : (1) The laboratory worker engaged in creating or trying out new ideas for the manufacture of a new or cheaper product. (2) The routine worker engaged in routine tests for the examination either of raw materials or of articles during or after their manufacture. (3) The 'service' worker engaged within the factory (as distinct from the laboratory) in solving the minor manufacturing problems of day-to-day occurrence.

Such differences in the work and in the environment of the work demand different mental abilities and different traits of temperament and character. The first group will be drawn chiefly from graduates in science with an honours degree and postgraduate training in research. No one could reach this standard without a high level of intelligence. These qualifications, however, do not ensure the possession of great inventive capacity or powers of imagination, without which the greatest discoveries are impossible. Although this type of work is in some aspects indistinguishable from that of an academic laboratory worker, yet the atmosphere in which the work is carried on is very different. Security of tenure as known to the academic worker does not exist ; in large organizations there may be virtual security, but that security depends on the continued success of the firm.

The industrial research worker has to face the fact that his firm must make profits even though he may have little share in them, and in some organizations there is a more blatant insistence on the profit-making than is either necessary or profitable. His work, too, will probably have to be kept secret to the firm, so that he has less chance of obtaining the personal prestige possible to his academic colleagues through the publication of researches. Hence the man who wants to work with a background of economic security and freedom to pursue his own path may find difficulty in adjusting himself to the industrial environment.

Such being the case, we have the somewhat anomalous position that the industrial research worker needs to be more academic than worldly in 
outlook, temperamentally more introvert than extrovert. There is some truth in the statement that academic training has insufficient reference or resemblance to working conditions in industry or commerce. The methods therefore learnt in the university should be supplemented by a training in the different methods, techniques and environmental conditions.

Industry, on the other hand, has not always realized what it demands, and has overlooked the fact that the very qualities being sought need for development a different general environment from that of the factory proper.

The selection of the research director is very important. His qualities were discussed in NATURE of January 20,1940, p. 81. More is required of him than ability to do research work. So far as his staff is concerned, he must be able to manage his subordinates, recognize genius and talent when he sees them, must never claim as his own without acknowledgment the ideas of others, and he must be in easy contact with his staff, not limiting his contacts to adverse criticism; in short, he must be scientific in regard to himself and to his environment as well as to his investigations-a much more difficult problem.

With advancing years originality tends to decrease. What then is the future of the scientific research worker? One suggestion is that he should have opportunities of learning other aspects of the industry, namely, those requiring the qualities of the older rather than of the younger worker. The research department should not be isolated from the other departments. His scientific training may prove invaluable in fields other than the laboratory. The problem ought also to be faced of whether research laboratory work can be a satisfying life-work for all those who enter it.

The routine scientific workers are recruited from boys who have not had a university education, and for this work high intelligence and creative ability are not necessary. Although routine work is not considered boring by all workers, yet investigation has shown that the more intelligent workers tend to experience a greater degree of boredom than others. There are some people who voluntarily earn their living by work that makes no demands on their intelligence, because they want their minds to be fresh for creative work outside office hours; but they are exceptions.

Temperamentally, the routine worker should be steady, placid and patient, able to find something of interest in routine work if only because to-day is another day. He should be able to detach his mind from work which is purely repetitive, and think of other things. The same problems of repetitive work that have been studied in the factory and office will be found relevant to routine scientific work. This means that the ambitions, keen, erratic boys with high intelligence are welladvised not to take up this work, unless it is specifically a stepping-stone to other work. In any group of these workers, however, there will be found some who are capable of more independent work. These should be allowed opportunities for further education.

Some scientific workers prove better at implementing than obtaining the results of research. They may, while being of a scientific attitude of mind and qualified in science, be more interested in the world and people outside themselves. That is, they prefer the works to the laboratory, so they are rather 'works scientists' under a works manager than 'scientific workers' under the research manager. Since the day-to-day problems brought to such a worker may be very varied, he needs as a basic qualification an honours degree, useful sometimes negatively in giving him information about what is not known as well as positively about what is known. On leaving the university or in the vacations he should have had first-hand experience of an industrial works, since his work will have to be done in collaboration with foremen and practical workers. He must therefore be able to understand the difficulties and explain the solutions when found. He will thus need a more outstanding personality than the laboratory worker.

Such in outline being the general situation, Dr. Myers asks whether the industrial psychologist can do anything to help. He makes three suggestions. In the first place, there should be a systematic study by trained people of the requirements of the various branches of research work, and tests devised, where they are not already in existence, to be used as a help in selection. Dr. Myers quotes an investigation which showed that a group of workers, who were recruited from about the same educational level as the routine scientific workers, required for their work considerable foresight, sustained 'distributed' attention, manipu lative ability, intelligence, mechanical ability, judgment of time and colour, etc., while temperamentally they had to be tested for thoroughness, reliability and self-confidence among other desirable qualities. Some of these can be measured with 
considerable reliability by objective tests ; others can only be assessed as the result of an interview. Directors of research, like directors and managers in other parts of the organization, usually believe that they can choose staff by some magic gift peculiar to themselves, but unfortunately for the belief, misfits are not uncommon.

A study of the best methods of training beginners is important. It is odd that while the utmost care is taken in the training of beginners for sports, industry has been slow to apply the same principles, and entrants are expected to pick up their work by helping or watching proficients. Investigation has shown that a higher degree of efficiency can be attained by scientific training methods. It is possible that the same will be found true in the case of the laboratory workers. 'Trial and error' methods are extremely wasteful.

Lastly, a systematic study of grievances might lead to considerable improvement. The presence of a major grievance is an expensive luxury for any management. It is true that there are always with us the congenital grousers, but these can easily be recognized and are rarely taken seriously; but a legitimate grievance ignored by those who could remedy it is a danger point. From preliminary observations, excessive hours under strain or friction, inadequate holidays, fear of dismissal, and too great rigidity of organization are major grievances. Where the grievances result from a lack of understanding on the part of the workers, a reasoned explanation can do much to restore contentment; where the cause of grievances can be remedied it should be. Other industrial employees have benefited from a scientific study of their grievances, and there is no reason to suppose that scientific workers would be exceptional in this respect. The word 'scientific' has perhaps tended to isolate these workers from others; but all those who exchange the work of their hands or heads for the wherewithal to live have much in common, whatever may be the nature of the work.

\section{THE BEHAVIOUR OF THE CUCKOO}

The Truth about the Cuckoo

By Edgar P. Chance. Pp. xvi $+208+38$ plates. (London: Country Life, Ltd.; New York: Charles Scribner's Sons, 1940.) 12s. 6d. net.

$\mathrm{M}^{\mathrm{B}}$ R. EDGAR CHANCE has produced a book which will be of interest not merely to those who watch and study birds and derive profit and pleasure from so doing, but also to the avian physiologist who concerns himself with the functions of the living parts of the bird and attempts to compare and correlate the processes which go on in them. This second book is fuller and more definite than the author's earlier one, entitled "The Cuckoo's Secret", and conclusions which were originally put forward as tentative or partly true are now regarded as established. No one who reads these books can fail to admire the industry, the patient deliberation and the ingenuity shown by the author in conducting his investigations, which have extended over more than twenty years.

The principal problem which Mr. Chance set himself to solve was whether the cuckoo laid its egg and then carried it in its beak (or in its gullet) before depositing it in another's bird's nest, or whether it laid it directly into the nest of the foster parent. The records given here conclusively prove that the latter is the actual method, and that even in the case of domed nests with small entrance holes the egg is projected right into the nest, the bill playing no part in the process.

There are other cuckoo problems dealt with by the author, and one of the most discussed of these relates to the observation that speaking generally each bird tends to parasitize a particular species of fosterer, there being a general likeness between the eggs of the parasitizing cuckoo and those of the fosterer. It is noted, however, that there are exceptions and some of these are described by the author. Prof. Punnett, in an instructive appendix on the genetical aspect of the cuckoo, urges that the collector should pay more attention to these exceptional eggs, and shows how it might be possible, by acquiring data on this and other matters capable of investigation in the field, to obtain a closer insight into the genetics of the species. Prof. Punnett is inclined to assume that the cuckoo is polyandrous; but Mr. Chance from his own observations is of the opinion that the bird very usually pairs for life. There is nothing unlikely about this (though Dr. Chapin, who contributes a foreword, thinks differently). For it 